Reviews

the heart of a disease curtain, one hopes that efforts to reduce their insecurity will continue to attract the attention of diverse and thoughtful scholars, policymakers and activists. One suspects, however, that for much of humankind the next century will hold its full share of threat.

\title{
How to Create and Nurture a Nature Center in Your Community by Brent Evans and Carolyn Chipman-Evans, (1998) Austin: University of Texas Press, xv, 250 pp.
}

\section{Reviewed by Matthew Oppenheim, Burbank, CA.}

This book, a visual as well as a spiritual and intellectual delight, gathers the collective wisdom gained from nature centers across the U.S. It is a "how-to" book for developing the activism and administrative expertise to successfully start a nature center. It weaves into this practical discussion reflections from Native American traditions and from naturalists such as John Muir, as well as countless inspiring stories by visitors and avid volunteers who have been transformed by their experiences of nature. The authors interject their own personal experiences from the Cibolo Nature Center - near the Texas Hill Country town of Boerne - which they helped create in 1988. The visual experience of the nature center is always close at hand in this book, conveyed through photos of activities and graphics from building floor plans and detailed drawings of native flora.

The authors claim that the awakened consciousness from the nature center experience can lead to sustainable planetary change. Yet the link between a small local nature sanctuary and the remedy to rapid environmental degradation is not clearly established. While enjoying the this book's inspiring and richly realized stories, we also must look critically to see whether and to what extent the nature center is indeed a pivotal local response to the need for encompassing change.

The book begins with a quote attributed to Chief Seattle - "and what is there to life, if a man cannot hear the lonely cry of the whippoorwill ..." - and the personal experiences of the authors that inspired the vision and sense of mission for the book. They tell the story of their own Cibolo Nature Center, followed by short descriptions of what they consider to be sixteen of the more successful nature centers across the country. Whether Chief Seattle actually spoke the words later attributed to him is open to question, but their invocation here capitalizes on the popular view that privileges indigenous ecological wisdom.

The book then considers the mission and purpose of nature centers: "A nature center protects a piece of ground that can both inspire and teach." The authors discuss the interdependent issues of conservation, education, and recreation, and quickly move on to pragmatics. Facilities are discussed first, from designing buildings and trails to live animal enclosures and botanical centers. Then come "Program Possibilities." We learn about "maple sugaring" projects, "Enchanted Halloween" parties, as well as more traditional activities, from nature walks to wildlife seminars. There are tips for presentations and details of the Cibolo education program. A more lengthy discussion of the process of creating your own center follows. As always, the chapter starts with an inspiring quote, this time from Margaret Mead: 
Reviews

Never doubt that a small group of thoughtful committed citizens can change the world. Indeed, it, s the only thing that ever has.

The next step is to consider ways of community organizing. We again are rallied around the cause, before given practical advice: "As modern life separates families more and more, with fewer moments of beauty and connectedness, a saunter together through nature can do more than a dozen family therapy sessions." We are encouraged to work with Chambers of Commerce, city planners, farmers and ranchers, church ministers, and health care providers.

For my own work, as an applied anthropologist with a life-long passion for grassroots organizing and educational transformation, I found a wealth of information on group process and neighborhood organizing, as well as practical advice on resolving group conflicts and mentoring volunteers. Most important, we are reminded regularly that true social change must be inspired by that which nourishes the soul. In this book this source of nourishment is the transcendent, peaceful, centering experience that just about all of us are said to gain from nature. The authors want you to know and internalize their sense of mission. We are led to believe that if our consciousness awakens, sustainable global change is close at hand. While the authors acknowledge that many nature centers have led battles to save endangered species, or to protect critical wildlife or ecologically vulnerable areas, nature center lands are often carved out of otherwise undevelopable areas, places that when taken out of local tax base are less likely to be contested.

Organizational development issues are raised next. We are taken through the growing pains and triumphs of starting an organization, moving from the "seed" phase, to conflicts with individuals and egos, adolescence, to maturation, and mid-life crisis. All those who have been involved with community organizing will appreciate the authors' candor and sense of organizational evolution. We are reminded of how useful it is to adopt an outlook that whatever happens is of benefit to our learning and growth. The authors help us develop our vision and action plan, bylaws, and articles of incorporation. We are presented with ideas for building membership, developing staff, and finding interns.

We are then taken through the details of running and developing our nature center. We learn about fundraising and letters of support. There is a list of community resources to help us and a sample newsletter and detailed operational budget. An outline for writing grants is presented in such a succinct style, that I am eager to show it to my friends in a new community-based organization in Los Angeles. A section on land management addresses predator management, use of water, and ways to feed the local fauna so they don,t become dependent on handouts. Trail building details are followed by suggestions for developing a master plan so that all details discussed in the book come together in a strategic process.

Finally there is an inspirational talk to keep us motivated in a chapter entitled "Hope:" "As your project evolves, so does your message, the lesson you wish to teach. As your love of nature depends, you will begin to sense how vital it is that you act upon your beliefs." We are reminded that we will learn to heal ourselves as we nurture our planet, and that we must sustain our internal wildness and creativity. The authors want to plant a seed to be nurtured, and hope that they have somehow served as midwives in the process. Finally, we find quotes from George Bernard Shaw, Edward Abbey and Jacques Cousteau. An appendix lists organizations across the U.S. and publications where we can go for further advice.

We have been rallied, mentored, and inspired to take action. With my renewed spirit, however, I wondered what steps the authors would recommend to channel this back to our despoiling urban economies. Do psychic and spiritual renewal and a nearby nature preserve lead to systemic changes? Is there some sort of cumulative "change in consciousness" that occurs, or is the renewal of the spirit a catalyst for more directed change that truly remedies the underlying cause of environmental degradation? Can this change of consciousness address the real cause of environmental problems; the march of global capitalism that deforests, disinvests indigenous peoples, and divests us of thousands of plant and animal species?

Critical issues emerge from what is presented in the book and many "ecologies," both human 
Reviews

and "natural" are glaringly absent, as are countless ethnic groups from its photos. I would like to address these issues by contrasting the world of the nature center portrayed in the book with my experience with ecological issues of a different sort, in an urban barrio on the outskirts of Los Angeles. Here, a large local park, the neighborhood,s only access to "nature" has been re-zoned for commercial use, leaving a small remaining section that contains a public swimming pool (now closed), a few park benches and a touch of grass. One of the industries planted on this land was a chemical storage facility, now one of the many on the local list of the EPA charged with chemical leakage. I would guess that few of the residents benefit from the kind of nature center in the book, either as a space for regeneration and renewal or as a center for activism. Penalties for toxic waste are dramatically higher in areas of predominantly white populations than African American or Latino, and action for cleanups begins as much as $42 \%$ later for these minority groups and the percentage of African Americans and Hispanics living in polluted areas far exceeds the white population (Bullard 1994).

The urban barrio and the suburban nature center have a good deal of distance between them; while not necessarily a great distance physically, the political, intellectual, economic and cultural gap is huge. The actual human inhabitants may rarely cross each other, s paths, except to the extent that a bus of urban children from our barrio may be lucky enough to visit a nature center for one day a year.

Ethnically, we find many urban immigrants coming from lands where they and their ancestors farmed and were part of the land. Their barrio yards contain healing herbs, lemon trees and chickens, while in the public streets the city council ignores its responsibilities to plant and care for trees, and people live in constant fear of violence. Economically, our urban inhabitants are under constant threat, as factories take over residential areas, and then close down and move elsewhere in the hunt for cheaper labor. Affordable transportation and housing are beyond reach for many, and it is a struggle to keep open the last remaining bank branch. All the while, the suburban nature sanctuary is not under apparent threat of closure.

Do nature centers point towards a solution to the environmental degradation that forces hundreds of thousands to flee their homeland, ending up in ecological wastelands, whether Mexico City, Calcutta or Los Angeles? This book makes no reference to this type of sustainable solution. In urban schools children learn about endangered species, rapid deforestation, toxic waste and global warming, but where is their space to connect and embrace nature and to act towards meaningful change?

In How to Create and Nurture A Nature Center, we are encouraged to leave these types of issues behind and gather inspiration and renewal from a land unaffected by poverty. We are reminded of the transcendent healing power of nature that heals our souls and gathers wisdom. But in saying this, is the book fostering an escapism from the real world issues that truly shape our futures? Are we running to an imagined space, and by doing so contributing to neglect of the real struggle for our planet?

The crux of the issue is whether there can be limited good for a few, while the welfare of the whole is neglected? Along with this is the acknowledgment that if we are not addressing the whole of an issue, we are working with limited and fragmented solutions and may well be contributing to the problem if we do not address truly systemic change.

A recent issue of Whole Earth magazine addresses the urgent need to defend "the commons." Here the commons is a local as well as a global psychic place, tied to heritage and nature as well as to economics and values. Indian philosopher Prabhat Ranjan Sarkar challenges us to develop an equilibrium between our socioeconomic and environmental commons, grounded on a spiritual sense of ecology:

We should remember that the sky and air, the hills and mountains, the rivers and forest, the wild animals and reptiles, the birds and fish and all sorts of aquatic creatures and plants are all inseparably related to one another. (1987: 62)

In his social theory, PROUT (the Progressive Utilization Theory) we are encouraged to form 


\section{Reviews}

ecologically sound regional economies, challenging the economic and political forces that exploit natural and human environments (Sarkar 1992). Here, inspired by spiritual renewal, a personal ethic of non-harmfulness and service, and led by locally-governed cooperatives, there is a balance between individual freedom and social responsibility. Regional economies tied to local watersheds and cultures help prevent over-industrialization by balancing agricultural, industrial, service and retail sectors. Each region collaborates on a national and then global scale to guard rivers and oceans, to protect indigenous culture, and prevent exploitation.

\section{References Cited:}

Bullard, Robert D.

1994. “Overcoming Racism in Environmental Decisionmaking," Environment, (May 1994): 11-20, 39-44.

Sarkar, Prabhat Rajan.

1987. Neo-Humanism in a Nutshell, Part 2, Calcutta, India: Ananda Marga Pracaraka Samgha.

Sarkar, Prabhat Rajan.

1992. Proutist Economics: Discourses on Economic Liberation, Calcutta India: Ananda Marga Pracaraka Samgha.

\section{Adaptation to Malaria: The Interaction of Biology and Culture. Edited by Lawrence S. Greene and Maria Enrica Danubio. xiv + 490 pp. New York: Gordon and Breach. 1997.}

\section{Review by Kevin M. Kelly, University of Iowa College of Public Health.}

Malaria currently affects over 400 million people worldwide. Seeing that this number continues to grow, Greene and Danubio (p. 2) rhetorically ask whether "future health endeavors might profit from an understanding of the way in which human populations have adapted to malaria in the past--both biologically and culturally." This volume highlights their insightful statement.

At the outset, potential readers should be warned that despite the title, this informative, interdisciplinary volume is not a treatise on the broad scope of human adaptation to malaria. Rather, an impressive list of contributors examine glucose-6-phosphate dehyrogenase [G6PD] deficiency, its physiology, genetic variants, distribution and interaction with cultural adaptations to malaria.

The volume's 16 well-referenced contributions are arranged under three section headings [Table of Contents]. The first section explores the molecular genetics, biochemistry, epidemiology and clinical sequallae of G6PD-deficiency. In Chapter 1, by Gaetani and Ferrans, describes the 